Heart Failure

\section{A Silver bullet to treat heart failure}

RJ Hajjar and RJ Samulski

Gene Therapy (2006) 13, 997. doi:10.1038/sj.gt.3302747;

published online 9 March 2006

Heart failure (HF) continues to be a progressive disease with ever increasing morbidity and mortality in the western world. ${ }^{1}$ While progress in conventional treatment modalities is making steady and incremental gains to reduce HF mortality, there remains a need to explore new and potentially therapeutic approaches. ${ }^{1}$ To that end, several animal models of heart failure have been used to test these novel therapies. A genetic strain of Syrian hamsters with a large deletion in the $\delta$-sarcoglycan (SG) gene (TO-2 strain), are characterized by skeletal muscle myopathy, and severe cardiac dilation and cardiomyopathy, which primarily contributes to the very high mortality in these animals. ${ }^{2}$ In a recent study, Zhu et al..$^{3}$ reported that a single injection of adeno-associated type- 8 vector carrying the human $\delta$-SG gene enhanced contractile function in the hearts of these diseased hamsters, restored exercise capacity and survival to normal, and improved skeletal muscle function.

In these studies, the investigators used a novel AAV serotype, namely type 8 , which they had previously shown to be highly efficient in crossing the blood vessel barrier and having great efficiency in transducing skeletal and cardiac muscles. ${ }^{4}$ Different AAV serotypes have different tropisms to various organs ${ }^{5,6}$ but the features of AAV8 made this specific vector ideal for targeting a disease state such as limb girdle muscular dystrophy (LGMD) that affects both cardiac and skeletal muscles. The authors further refined their AAV8 constructs by incorporating a double-stranded DNA vector for speedier and stronger expression and by using the synthetic musclespecific promoter (SP) C5-C27. ${ }^{3}$ The experiments were carried out in neonates and in adult animals. In both groups, the reversal of cardiac and skeletal abnormalities were dramatic showing that gene transfer of the human SG gene by AAV8 pre- vented the development of heart failure and skeletal abnormalities. One of the most exciting results was that long-term human $\delta$-SG expression in these animals led to the prolongation of the lifespan of the diseased animals. In fact, TO-2 hamsters died of heart failure at 32-43 weeks of age (median survival time, 37 weeks), however, all of the AAV8-treated TO-2 hamsters survived beyond 48 weeks.

LGMD, however, represents only a very small fraction of $\mathrm{HF}$ in the general population. ${ }^{7}$

Most HF patients have various etiologies including coronary artery disease, hypertension, valvular disease, diabetes, infection, infiltrative syndromes or inflammation resulting in a myocardium with a mixture of replacement fibrosis, and dysfunctional myocytes. ${ }^{8}$ The abnormal contraction in these cardiomyocytes is caused by a wide variety of molecular changes with the dysregulation of thousands of genes. ${ }^{8,9}$ There are several mechanisms, however, that seem to be central to the pathogenesis of contractile dysfunction in heart failure. These include: (1) a defect in sarcoplasmic reticulum function, which is responsible for abnormal intracellular calcium handling, (2) activation of pro-apoptotic pathways, (3) dysregulation of beta adrenergic signaling, and (4) electrical remodeling. ${ }^{8,9}$ Targeting these pathways by gene transfer seems to improve overall function in failing hearts. Advances in the understanding of the molecular basis of myocardial dysfunction has, together with the evolution of increasingly efficient gene transfer technology, placed some cardiovascular pathophysiologies within reach of gene-based therapy.

The results of $\mathrm{Zhu}$ et al. ${ }^{3}$ will clearly pave the way for clinical gene therapy trials using AAV8 and $\delta$-SG gene in human LGMD. More generally, it will allow new strategies with this and other novel vectors to be used to modulate various path- ways in the more common forms of heart failure, ultimately providing novel therapeutic approaches for the management of the majority of heart failure patients. The recent description of AAV9 which has even higher cardiac tropism will further the drive towards clinical gene therapy for heart failure.

RJ Hajjar is at the Harvard Medical School, Massachusetts General Hospital, 149 13th street, CNY-4, room 4215, Charlestown, MA 02129, USA. E-mail: rhajjar@partners.org and RJ Samulski is at the Gene Therapy Center, 7119 Thurston bldg, CB \#7352, Chapel Hill, NC 27599,USA. E-mail: rjs@med.unc.edu Published online 9 March 2006

1 Hunt SA, Abraham WT, Chin MH, Feldman AM, Francis GS, Ganiats TG et al. ACC/AHA 2005 Guideline Update for the Diagnosis and Management of Chronic Heart Failure in the AdultSummary Article. A Report of the American College of Cardiology/American Heart Association Task Force on Practice Guidelines (Writing Committee to Update the 2001 Guidelines for the Evaluation and Management of Heart Failure). J Am Coll Cardiol 2005; 46: 1116-1143.

2 Nigro V, Okazaki Y, Belsito A, Piluso G, Matsuda Y, Politano L et al. Identification of the Syrian hamster cardiomyopathy gene. Hum Mol Genet 1997; 6: 601-607.

3 Zhu T, Zhou L, Mori S, Wang Z, McTiernan $C F$, Qiao $C$ et al. Sustained wholebody functional rescue in congestive heart failure and muscular dystrophy hamsters by systemic gene transfer. Circulation 2005; 112: 2650-2659.

4 Wang Z, Zhu T, Qiao C, Zhou L, Wang B, Zhang $\mathrm{J}$ et al. Adeno-associated virus serotype 8 efficiently delivers genes to muscle and heart. Nat Biotechnol 2005; 23: 321-328.

5 Du L, Kido M, Lee DV, Rabinowitz JE, Samulski RJ, Jamieson SW et al. Differential myocardial gene delivery by recombinant serotype-specific adeno-associated viral vectors. Mol Ther 2004; 10: 604-608.

6 Hacker UT, Wingenfeld L, Kofler DM, Schuhmann NK, Lutz S, Herold T et al. Adeno-associated virus serotypes 1 to 5 mediated tumor cell directed gene transfer and improvement of transduction efficiency. J Gene Med 2005; 7: 1429-1438.

7 Mascarenhas DA, Spodick DH, Chad DA, Gilchrist J, Townes PL, DeGirolami U et al. Cardiomyopathy of limb-girdle muscular dystrophy. J Am Coll Cardiol 1994; 24: 1328-1333.

8 del Monte F, Hajjar RJ. Targeting calcium cycling proteins in heart failure through gene transfer. J Physiol 2003; 546: 49-61.

9 Hajjar RJ, del Monte F, Matsui T, Rosenzweig A. Prospects for gene therapy for heart failure. Circ Res 2000; 86: 616-621. 